frequently seen in patients up to the midtwenties (Fig.), suggesting delayed bone maturation.-We are, etc.,

Alan Richens.

St. Bartholomew's Hospital,

David Rowe.

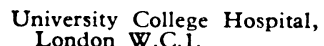

1 Kruse, R., Monatsschrift für Kinderheilkunde,

2 Rudra, M. N., De, S., and Rudra, M. S., New England fournal of Medicine, 1969, 280, 1242 3 Dent, C. E., Richens, A., Rowe, D. J. F., and
Stamp, T. C. B., British Medical foumal, 1970 , Stamp,

- Canapa-Anson, R., and Rowe, D. J. F., fournal of Clinical Pathology, 1970, 23, 499.

\section{Fibrosing Alveolitis and Renal Tubular Acidosis}

SIR,-The paper by Dr. A. M. S. Mason and others (5 December, p. 596) on fibrosing alveolitis with renal tubular acidosis has prompted us to write of a case under our care at present. The seven cases of fibrosing alveolitis studied by them had a normal response to an ammonium chloride load. We have seen a renal acidification defect develop in a woman with Sjögren's syndrome, fibrosing alveolitis, and hyperglobulinaemic purpura.

The patient presented in 1954 at the age of 54 with keratoconjunctivitis sicca and xerostomia. Three years later she developed Waldenström's hvperglobulinaemic nurpura and fibrosing alveolitis. In May 1969 she was ahle to elaborate urine of $\mathrm{pH}$ less than 5.3. She was admitted to Northwick Park Hospital on 11 November 1970 having recently had a sore throat which had made her reluctant to drink. On examination she was grossly dehydrated and confused. After rehvdration she remained acidotic (plasma bicarbonate $15 \mathrm{~m} \mathrm{Eq} / \mathrm{l}$.) and despite this her urine $\mathrm{pH}$ was never below $6 \cdot 2$.

Thus between May 1969 and now this patient has developed renal tubular acidosis. In sequence our patient presented with Sjögren's syndrome, huperglobulinaemic purpura, fibrosing alveolitis, and renal tubular acidosis. We believe that this is the first occasion on which an acidification defect has been seen to appear in such a case. Full details are to be presented. ${ }^{1}-$ We are, etc.,

A. M. Zalin. JOAN WEEPLE.

Northwick Park Hospital,
Harrow, Middx. M. GUMPEL.

\section{REFERENCE}

1 Gumpel, M., Proceedings of the Royal Society of Medicine. In press.

\section{Ileorectal Anastomosis for Ulcerative Colitis}

SIR,-In your leading article (5 December, p. 572) you appear to try to demolish Aylett's work in conservative surgery of inflammatory disease of the colon. I have attended discussions where the conservative and the radical schools have met in head on clash over a subject which should, of course, be a matter of judgement. I agree that there are cases in which panproctocolectomy is obviously indicated, but there are many cases that can be satisfactorily treated by ileorectal anastomosis.

Surgical treatment culminating in ileostomy can only be justified in severe cases, but the indication for resection with anastomosis may readily be widened, so offering the prospects of surgical relief to a larger number of patients who would otherwise be condemned to a life of incomplete medical treatment. The effects of recurrence or persistence of disease in the residual rectum appear trivial and easily controlled. Subsequent surveillance does not present a problem.

Although removal of the rectum certainly eradicates the disease, the danger of retention of the rectum appears to be exaggerated, and can be compared with the drawbacks of removing it. There is a high incidence of impotence in the male (and possibly in the female) following resection of the rectum. Perineal sinuses are common. Intestinal obstruction we all know occurs commonly after colectomy, while the ileostomy itself may suffer a number of mechanical complications. Having undertaken anastomosis, it may later be necessary after all to remove the rectum, but to do so although difficult should not tax the ingenuity of a proctologist.-I am, etc.,

\section{Southampton General Hospital, \\ Southampton, Hants.}

\section{T. ROWNTREE.}

\section{Coagulation Failure in Pregnancy}

SIR,-The significance of Dr. L. D. Courtney's experiment (31 October, p. 303) cannot be assessed without knowledge of the source of the $5 \mathrm{ml}$. of amniotic fluid, its temperature, the volume of fluid into which it was injected, and the nature of the uterine muscle preparation concerned. Fuchs and Wagner ${ }^{1}$ found that samples of human amniotic fluid obtained at all stages of gestation had a stimulant effect on isolated myometrium from pregnant women, and concluded that the artefact of changes of ionic concentration in the bath fluid plaved a major role in this effect. Nearly all the literature is consistent with their finding that whole amniotic fluid has a stimulant effect on isolated uterine muscle. The exception is the work of Stamm ${ }^{2}$ who observed inhibitory effects of relatively large amounts of amniotic fluid from therapeutic abortions on the isolated rodent uterus. Abrahams ${ }^{4}$ was unable to confirm his conclusions. All authorities are agreed that any pharmacological activity found in amniotic fluid in labour is stimulant to uterine muscle.

Landesman and Wilson ${ }^{5}$ have reviewed some of the work in the literature on pharmacologically-active polypeptides and lipidsoluble substances in amniotic fluid. More recently, Karim ${ }^{6}$ has observed the appearance of significant amounts of prostaglandins during spontaneous labour. My own conclusion was that the amount of other ether-soluble lipid stimulants present is usually at about the threshold for activity but is markedly increased when the amniotic fluid is meconium-stained.?
At the present time there does not appear to be any acceptable evidence that human amniotic fluid contains a specific uterine relaxing agent of clinical significance in relation to uterine hypotonia occurring after amniotic fluid infusion.-I am, etc.,

\section{F. Hawkins.}

Institute of Obstetrics and Gynaecology,

London W.12.

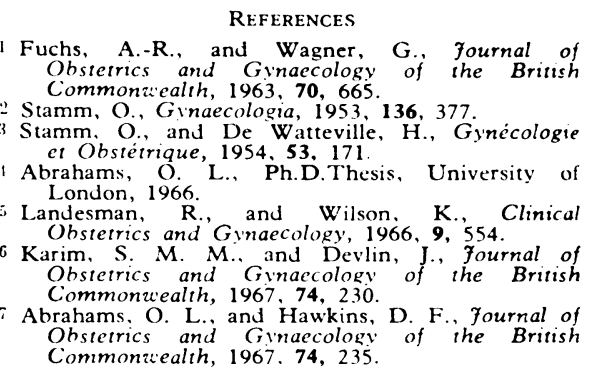

\section{Alcoholism and Industrial} Absenteeism

SIR,-As discussed at a recent meeting of the Royal Society of Medicine ${ }^{1}$ and in your leading article (14 November, p. 383), in dustrial absenteeism due to sickness is causing concern in industry and commerce. You go on to point out that in addition to the cost of sickness benefit the country loses the value of the absentee's production; that some staff members have more spells of sickness absence than others, $31 \%$ having at least three spells; and "the great advantage" that would follow ". . . if those liable to [frequent] . . . short-term spells of sickness absence . . . could be identified by other factors."

Problem drinkers and early alcoholics very often have such spells of absence, quite apart from marked impairment of performance even while at work. ${ }^{2}$ Alcoholics are found at all industrial levels, among managers as well as on the shop floor. Research and adoption of progressive policies by many American firms have shown not only the importance of alcoholism in causing great loss in industry but also that problem drinkers in industry can often be identified in relatively early phases, treated, and rehabilitated. ${ }^{3}$ Industry in Britain remains as indifferent to the alcoholic problem today as in the past, yet the cost of alcoholism to British industry has been variously "guessed" as being between $£ 100 \mathrm{~m}$. and $£ 250 \mathrm{~m}$. a year. ${ }^{2}$

Alcoholics employed in industry stand by reason of personality and relative social stability a fair chance of marked improvement or even recovery-if recognized early and treated. Industry is in a good position by means of early diagnosis to take preventive and early therapeutic action. Much unnecessary human suffering as well at material waste can thus be avoided. There is no reason why positive action should and could not start now.-I am, etc.,

St. Bernard's Hospital,

M. M. Glatt

Southall, Middlesex.

REFERENCES

1 Proceedinos of the Royal Society of Medicine. 1970, 63, 1131

Glatt, M. M., The Alcoholic, and the Help He Needs. Royston, Herts., Priory Press, 1970. hristopher, $\mathrm{D}$. Smithers Foundation, Under
standing Alcoholism. New York, Scribner, 1968. 